\title{
Design of the cooling system of diesel locomotive
}

\author{
Lin Dong \\ Weifang University of Science and Technology, Shouguang,Weifang, Shandong, 262700, China; \\ E-mail: Dlzs222@sina.com
}

Keywords: Diesel engine; The cooling system;The radiator.

\begin{abstract}
This paper mainly expounds the locomotive cooling system functions, composition and main components. On the function of the locomotive cooling system and plays an important role in the locomotive has a preliminary understanding. Then expounds several kinds of commonly used cooling technology, and basic working principle of numerous kinds of cooling technology and related role makes a simple elaboration. The former mainly expounds the process more research of the radiator.
\end{abstract}

\section{Introduction}

The constant improvement of the diesel locomotive power for locomotive cooling system heat dissipation is bigger and bigger. Due to limited by locomotive structure space and axle load, simply rely on the way to increase the number of radiator has already can't satisfy the requirement of the locomotive cooling capacity, therefore, need the structure of the locomotive cooling system and the radiator performance put forward higher request, make the cooling device with high performance, lightweight and high reliability. On the basis of the conventional cooling system design method, to study and put forward the process of the radiator. How much flow cooling system has a high cooling efficiency, simple structure, small water pump of auxiliary power consumption and cooling system components high working reliability, etc. This paper introduced the locomotive cooling system and its function, several cooling technology as well as to the existing process of radiator is studied and the analysis and calculation, and the three processes radiator radiator was tested to compare with single process. This topic for CKD9 type diesel locomotive cooling system design requirements, and present a new kind of multiple process radiator structure scheme. The plan and effective use of the radiator cooling water cooling air temperature difference, achieve the goal of improving the heat dissipating capacity.

\section{The locomotive cooling system}

The effect of the cooling system. The cooling system of diesel engine itself is with outside air cooling diesel engine oil, water, charge air cooling device synthesis, it includes surface type heat exchanger, radiator, fan device, air passage, shutters, and the radiator group, asked in the heat exchanger (used for cooling of diesel engine oil and pressurized air), consisting of water circulation pump and pipeline, the oil circulating system.

The classification of the cooling system. Diesel engine cooling system, the cooling way is different, generally can be subdivided into the ventilation cooling system, diesel engine water cooling system, charge air cooling system and all kinds of oil (oil, hydraulic oil, etc.) of the cooling system. The internal combustion engine cooling system can be summarised as the ventilation cooling system and two kinds of water cooling system.

\section{Major part of the cooling system.}

1)The radiator

The radiator is one of the essential parts of diesel locomotive. He employed to cool the cooling water of diesel engine and engine oil, hydraulic oil cooling water. 
2)Oil/water heat exchanger

In order to maintain the normal operation of the diesel engine oil temperature in the internal combustion engine vehicle uses the oil/water heat exchanger, oil in the cooling water to cool.

3)Cooling fan

\section{Research of the cooling system}

The existing several kinds of cooling technology. At home and abroad in recent years, the study of diesel locomotive cooling technology has made great development, and achieved great results. , such as shingles radiator cooling technology, the radiator dry type cooling system, and high temperature cooling, etc.

Shanklin heat cooling technology . Shanklin heat cooling technology, the so-called shinglier radiator, was on a radiator with two relatively independent water cavities, or hot water and cold water cavity. Low water cavity layout on the windward side, high temperature water cavity layout in the leeward side. Low temperature of cooling water and high temperature of the cooling water is conducted by the same stream of cooling air has cooled. According to heat transfer mechanism of the radiator, radiator the heat dissipating capacity of $\mathrm{Q}$ is the heat transfer coefficient $\mathrm{K}$, cooling area and the mean temperature difference of two fluid $\mathrm{F} \Delta \mathrm{t}$ decided its formula is:

$$
\mathrm{Q}=\mathrm{k} . \mathrm{f} . \Delta \mathrm{t}
$$

Improve the heat dissipating capacity $\mathrm{Q}$, can improve the heat transfer coefficient $\mathrm{K}$, increase the cooling area of $\mathrm{F}$ and logarithmic average temperature difference $\Delta \mathrm{t}$.

High temperature cooling technology. High temperature cooling technology, the so-called high temperature cooling diesel engine is by raising the temperature of the cooling medium (cooling water or oil), to increase the temperature difference between the cooling medium with outside air, improve the cooling ability of locomotive cooling device, at the same time, due to the cooling medium and the temperature of the cylinder, reduce the heat loss of diesel engine, improve the economic benefit of the diesel engine.

Dry cooling technology. Dry cooling: the so-called dry cooling is in locomotive diesel engine at low temperature and cooling water, cooling water is not into the water tank of the radiator and all return to the $\mathrm{AD}$ hot, or stored in diesel engine water cavity and low position in the line of cooling system. When the cooling water temperature rises to set the temperature of the cooling water into the radiator. Dry type cooling system still runs high and low temperature two independent cooling water circulation, to raise the temperature of cooling water, and then improve the ability to heat dissipation. Characteristics of dry type cooling water system:

1)Have effective protective ability. Do not accept diesel engine or oil, water temperature is lower in the radiator without cooling water, which can effectively prevent frost crack of the radiator and cooling water freezes, the diesel engine cooling water temperature is always stay in the appropriate range.

2)Cooling fan using compressed air type decorates. Compared with the aspirated, pressure type ornaments the wind cooling fan air inhaled by the low temperature, large density. In the same volume flow, a suction type more wind velocity, air quality and the constant heat consume less power.

3)Dry cooling water system is commonly pressure cooling, so that we can increase the cooling water boiling point elevations.

\section{Process design of radiator}

The design of the structure scheme. The constant improvement of the diesel locomotive power for locomotive cooling system heat dissipation is bigger and bigger. Due to limited by locomotive structure space and axle load, simply rely on the way to increase the number of radiator has already can't satisfy the requirement of the locomotive cooling capacity, therefore, need the structure of the 
locomotive cooling system and the radiator performance put forward higher request, make the cooling device with high performance, lightweight and high reliability. In order to adapt to the use of locomotive market demand at present, the existing diesel locomotive cooling technology and radiator manufacturing technology, on the basis of further improve the cooling capacity of the locomotive cooling system, improve system reliability and reduce the energy consumption in with detailed research, and puts forward the structure scheme of locomotive process more radiator.

Improve the radiator cooling capacity, mainly through increasing the heat transfer area of the radiator, radiator heat transfer coefficient and enhance the radiator cooling medium of the logarithmic average temperature difference. In this paper, the process of radiator, is along the depth direction through the radiator (cooling air flow direction) divided into order, autonomous of each other more than 2 and 2 processes. Through reasonable arrangement of cooling air and the same cooling system, cooling water flow direction and flow of the order can be more efficient use of cold and hot medium temperature difference, improve the quality of the radiator units and heat of unit volume, achieve the goal of improving cooling efficiency of cooling system. Figure 1 and figure 2 for the two kinds of structure diagram.

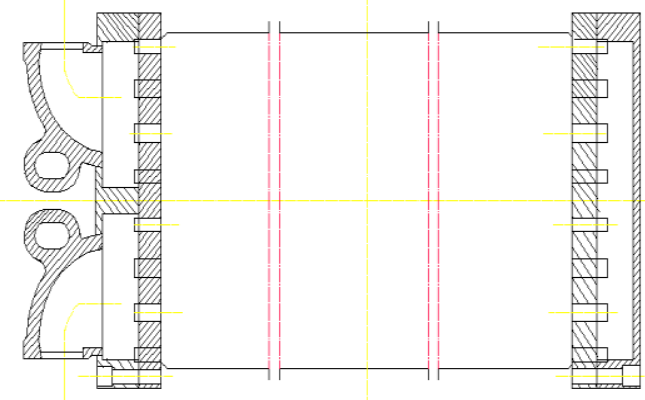

Figure. 1 The two processes radiator structure diagram

Shanklin radiator cooling technology, was developed by domain diesel locomotive research institute, a new technology of diesel locomotive cooling device in 1994 by the Ministry of railways rolling stock industry corp. This kind of radiator in March 1987 and September 1989 in ND2 type 191 and 037 respectively on a motorcycle, in October 1990 and April 1991 outfit Yu Dongfeng 9 type 0001 and 0002 on a motorcycle, in November 1992 and June 1993 again to shinglier way type radiator mounted Yu Dongfeng 110001 and 0002 on a motorcycle. The bench test, the water resistance test and actual application show that the shinglier radiator cooling technology to enhance the radiator cooling capacity, reducing the cooling unit length and the lower cooling equipment cost have an obvious effect. From the internal combustion engine depot, durian institute of internal combustion engine car radiator manufacturers and units adopts this new technology.

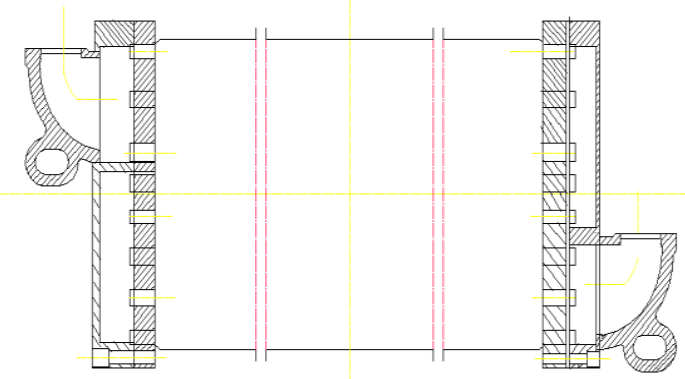

Figure. 2 The three processes radiator structure diagram 
Many within the process itself is the same radiator cooling water system of the whole process. Therefore, solve the rely on conventional cooling system of locomotive header pipe and different connection way to implement the process for the shortcomings of the water system, such as cooling water circulating through the long; water resistance increased; the pump outlet pressure higher.

To illustrate how the process can effectively improve the logarithmic mean temperature difference of the radiator, we selected the three process of radiator and three series of single process of radiator performance test results, the method of using heat transfer the NUT, two kinds of cooling system respectively calculated equivalent unit size of the radiator.

Table 1 Two kinds of radiator cooling system of the equivalent unit

\begin{tabular}{|c|c|c|c|c|c|}
\hline number project & \multicolumn{3}{|c|}{$\begin{array}{l}\text { Three series of single } \\
\text { process of radiator }\end{array}$} & \multicolumn{2}{|c|}{$\begin{array}{l}\text { Three parallel } \\
\text { three processes }\end{array}$} \\
\hline \multicolumn{6}{|l|}{ radiator } \\
\hline \multicolumn{3}{|c|}{1 The air flow rate $/ \mathrm{kg} \cdot\left(\mathrm{s} \cdot \mathrm{m}^{2}\right)^{-1} 10$} & 10 & 10 & 10 \\
\hline \multicolumn{2}{|c|}{2 Water flow $/ \mathrm{m}^{3} \cdot \mathrm{h}^{-1}$} & 12.36 & 12.36 & 12.36 & 12.36 \\
\hline \multicolumn{2}{|c|}{3 Number of sets of radiator } & 1 & 1 & 1 & 3 \\
\hline \multicolumn{2}{|c|}{4 Water flow rate $/ \mathrm{m} \cdot \mathrm{s}^{-1}$} & 1 & 1 & 1 & 1 \\
\hline \multicolumn{4}{|c|}{5 Heat transfer coefficient $/ \mathrm{kw} \cdot\left(\mathrm{m}^{2} \cdot \mathrm{k}\right)^{-1} 0.1000 .100$} & $0 \quad 0.100$ & 0.113 \\
\hline \multicolumn{2}{|c|}{6 Inlet temperature $/{ }^{\circ} \mathrm{C}$} & 40 & 40 & 40 & 40 \\
\hline \multicolumn{2}{|c|}{7 The water temperature $/{ }^{\circ} \mathrm{C}$} & 78 & 75.21 & 72.63 & 78 \\
\hline \multicolumn{2}{|c|}{8 Calculated heat release $/ \mathrm{km}$} & 39.01 & 36.15 & 33.49 & 39.80 \\
\hline \multicolumn{2}{|c|}{9 Total heat release $/ \mathrm{km}$} & 108.56 & & \multicolumn{2}{|c|}{$39.80 \times 3=117.78$} \\
\hline
\end{tabular}

Can be seen from table 1, three parallel three process radiators standard samples of total heat dissipating capacity of $117.78 \mathrm{kw}$, more than three and duplicate the process about $8 \%$ higher than that of the radiator the heat dissipating capacity of $108.56 \mathrm{kw}$.

In addition, depending on the result of the radiator bench test shows that the three process heat sink in the water speed is $1 \mathrm{~m} / \mathrm{s}$ when the water resistance of $0.0175 \mathrm{Mpa}$, single process radiator is $0.034 \mathrm{Mpa}$. So three processes than three series of single process radiator water resistance by about $3.83 \%$. Figures 3 and 4 for the two kinds of equivalent unit water flow diagrams.

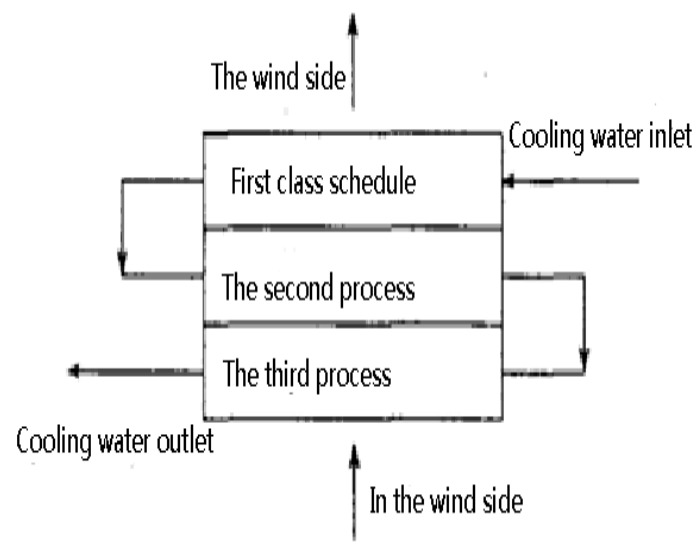

Figure. 3 Three parallel three processes radiator water flow diagram of standard sample equivalent unit 


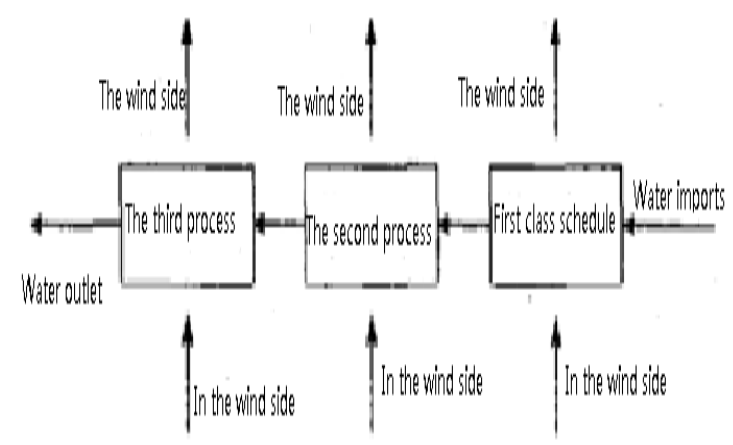

Figure. 4 Three series of single process radiator water flow diagram of equivalent units

\section{Conclusion}

In this paper, the process of radiator, more is placed on the basis of the conventional cooling system design method, inside the radiator for effective segmentation to achieve its structural design. And in view of the three processes radiator radiator party according to the structure scheme and the conventional single process, heat transfer mechanism of comparison analysis, three processes of radiator radiator heat transfer mechanism in relative to the conventional single process, explains the advantages of above; This paper expounds the three process basis and method of determining the radiator heat transfer coefficient; Using multiple process of radiator cooling system was put forward a new method for calculating the cooling capacity, gave three radiator and single processes radiator cooling performance design calculation results; Analysis the reason of the radiator water resistance decline; Expounds the hydrodynamics factors influence on erosion of radiator, etc. Work through the study of this article, illustrates the process of radiator in improving water resistance and heat transfer performance cooling system to reduce water radiator pipe end erosion have a significant advantage.

\section{References}

1. Ping Wang. Increase the accuracy of the diesel locomotive cooling capacity calculation study [J]. Journal of diesel locomotive, ploidy of 1996 (6).

2. Guoqiang Li. The practice of the modern type diesel locomotive cooling device [J]. Journal of diesel locomotive, 1996, 12 (2).

3. Qiyuan Tang. The comparison of several kinds of diesel locomotive cooling technology [J]. Journal of diesel locomotive, 1997, 1 (3).

4. Hui Wang, Liping Sun. The study of the process of internal combustion engine vehicle more radiator [J]. Journal of diesel locomotive, 2007, 19 (1).

5. Lifu Sheng, the qinghai-tibet railway diesel locomotive adopts dry cooling water system of the study [J]. Journal of diesel locomotive, 2005, 23 (2).

6. Shaoyuan Zhang, Ping Wu. DF8CJ ac drive freight locomotive dry type cooling system research [J]. Journal of diesel locomotive, 2003, 14 (11).

7.Cai Changming, ding. Li Changjie. DreamweaverUltraDev4 introduction and improve. Tsinghua university press, 2001

8.Xiong Songming, "standard of ASP.NET tutorial. Beijing aviation industry press, 2002

9.Zhao Fengnian, the instance illustrated pages. Beijing mechanical industry publishing house, 2001

10.XiBing, FIREWORKS 4 instances and operation. Beijing hope electronic publishing house, 2001 edition 